América sin Nombre, n. 21 (2016): 97-105

DOI: 10.14198/AMESN.2016.21.07

ISSN: 1577.3442 / eISSN: 1989-9831

Fecha de recepción: 28/09/2016

Fecha de aceptación: 05/11/2016
Puede citar este artículo como:

López de Mariscal, Blanca, y Vargas Montes, Paloma. «El debate y su función didáctica en el teatro de Fernán González de Eslava». Teatro breve virreinal. Miguel Zugasti (coordinador). América sin Nombre, 21 (2016): 97-105, DOI: 10.14198/AMESN.2016.21.07

Link para este artículo: http://dx.doi.org/10.14198/AMESN.2016.21.07

\title{
El debate y su función didáctica en el teatro de Fernán González de Eslava
}

\author{
Debate and its didactic function in the Fernán González de Eslava theater
}

\author{
Blanca López de Mariscal* \\ Paloma Vargas Montes** \\ Tecnológico de Monterrey
}

\begin{abstract}
Resumen
Este artículo explora las características formales y temáticas de la obra dramática de Fernán González de Eslava para mostrar la influencia del debate medieval en la producción del autor. A través del análisis de diversos coloquios de temas teológico, histórico y filosófico, se profundiza en el estudio del uso que González de Eslava le dio al debate para la transmisión de la doctrina y la persuasión de la audiencia.
\end{abstract}

Palabras clave: Debate medieval, coloquios, teatro novohispano, siglo xvı, Nueva Espańa, Fernán González de Eslava.

\begin{abstract}
This paper explores the formal characteristics and the themes of the dramatic work of Fernán González de Eslava. The discussion is focus on the influence of medieval debate in the author's dramatic production. Through the analysis of different pieces the paper shows how the debate was used by Gonzalez de Eslava as a tool to educate and persuade the audience in to the religious Christian doctrine.
\end{abstract}

Keywords: Medieval debate, colloquium, mexican colonial theatre, xvi Century, New Spain, Fernán González de Eslava.

A lo largo de todo el siglo xvI, los misioneros y los conquistadores que llegaron a territorios americanos introdujeron una nueva cultura que básicamente era heredera del pensamiento medieval. Aun cuando los hombres que arribaron al Nuevo Mundo podían ser considerados renacentistas, las tradiciones y la cosmovisión que llevaban en su horizonte de expectativas estaban arraigadas en el pensamiento del

* Blanca López de Mariscal es Doctora en Historia (Universidad Iberoamericana). Ha sido Directora del Departamento de Estudios Humanísticos (2002-2006), Directora de la Licenciatura en Letras Españolas (1997-2003) y Directora del programa en Maestría y Doctorado en Estudios Humanísticos del Tecnológico de Monterrey (2003-2015). Ha fungido como Vicepresidenta (2010-2013) y Secretaria (2004-2010) de la Asociación Internacional de Hispanistas. Es miembro del Sistema Nacional de Investigadores, nivel II.

** Paloma Vargas Montes es Doctora en Literatura Hispánica (Universidad de Navarra) y en Historia (École des Hautes Études en Sciences Sociales). Es investigadora posdoctoral del Tecnológico de Monterrey adscrita al proyecto de investigación Patrimonio Cultural, en donde realiza estudios crítico textuales para el rescate de manuscritos custodiados por la Biblioteca Cervantina. Es miembro del Sistema Nacional de Investigadores, nivel C. 
medioevo, de tal manera que los usos, las costumbres y tradiciones que enraizaron en los virreinatos españoles, en realidad tienen su origen más en el mundo medieval que en el renacentista, el cual en los primeros ańos del siglo xvi aún no se había consolidado en la Península Ibérica. La literatura de debate y su pervivencia en el teatro novohispano es un buen ejemplo de la forma en que la herencia medieval se presenta en el Nuevo Mundo y da origen a una producción dramática americana que tendría gran aceptación a lo largo del siglo XvI.

Los debates literarios de la Edad Media, que gozaron de una enorme popularidad en Espańa, pasaron a los nuevos territorios de América con diversos ropajes, a manera de coloquios, disputas, diálogos latinos..., pero sobre todo solapados en diversas piezas de teatro escolar con tema religioso, no catequizante y con carácter esencialmente didáctico y moralizante. Un buen ejemplo de ello se puede encontrar en algunas de las piezas que forman parte de la serie de Coloquios espirituales y sacramentales de Fernán González de Eslava.

Los debates medievales castellanos solían organizar la argumentación a partir de la presentación de una disputa entre dos antagonistas que enfrentaban posturas diferentes frente a una cuestión de carácter religioso, económico o social. Esta fórmula, cuyo contenido dialógico tenía una enorme carga de teatralidad, siguió ocupando a los poetas del Nuevo Mundo, que la utilizaron del mismo modo en que lo habían hecho los letrados medievales, tanto en Europa como en la Península Ibérica. En ella los antagonistas se enfrascan en un enfrentamiento verbal para disputar de forma dialéctica algún asunto que resulta importante comunicar al receptor. Durante el debate cada uno de los personajes, representantes de dos puntos de vista opuestos, «trataban de persuadir a su contrincante de la primacía de su propia causa, de su propia persona o de su conducta, podían ser indistintamente figuras de la vida real o personificaciones alegóricas según el tema discutido» (Franchini 2001, 11).

Enzo Franchini considera que, aunque en España se han conservado solamente nueve obras que pertenecen al género de debate, se localizan huellas «más o menos manifiestas del género» en piezas de diversa estructura y temática, como el Libro de Alexandre, el Libro de Apolonio, el Libro del Buen Amor, el Corbacho y los poemas de Gonzalo de Berceo, entre otros. En ellas se refleja la tendencia marcadamente medieval de concebir al mundo de manera dual, "polarizado en parejas de contrarios que se oponen para eliminarse o conciliarse», ya que los debates medievales no eran «sino manifestaciones literarias de la actividad intelectual más difundida en las escuelas y universidades medievales: la disputatio escolástica, de la que -conforme a la creencia de la época- habría de brotar la verdad» (Franchini 2001, 19).

Se trata de una fórmula dramatizada cuya permanencia se puede localizar en obras muy diversas «como por ejemplo los poemas de Gonzalo de Berceo, en donde la presentación literaria de disputa entre dos personajes manifiesta el buen conocimiento del género de los debates» (Franchini 2002, 377). Esta fórmula bien podría haber sido la base para lo que González de Eslava concibió como sus Coloquios espirituales y sacramentales, piezas que tienen por sustento un encuentro dialógico entre dos o más personajes, en el que se discuten asuntos que es importante mostrar al destinatario. Referente a los coloquios de Eslava, ya Rojas Garcidueñas y Juana Martínez Gómez se habían preguntado sobre la posibilidad de analizarlos aplicándoles la óptica o las normas del teatro de su época, cuestionándose si se trataba realmente de piezas dramáticas, aun y cuando las posibilidades de representación fueran escasas. Martínez Gómez señala «las dificultades que entraña el decorado en algunas ocasiones» (118), y más aún otro tipo de dificultades como los numerosos cambios de lugar o la gran cantidad de personajes que actúan simultáneamente. Sabemos, sin embargo, que los coloquios de Eslava sí fueron representados. Beatriz Mariscal Hay considera que son una muestra privilegiada de la producción dramática de «circunstancia» y que, aunque son escasos los datos precisos sobre su representación y las fechas de composición, el hecho de que sean piezas de "circunstancia» en algo ayuda para inferir estos datos. Además, de algunos de ellos tenemos incluso fechas exactas de la representación, pero el solo hecho de imaginarlos llevados a la escena con su escasa construcción dramática ha hecho que algunos críticos -tal por ejemplo José Rojas Garcidueñas- cuestionen la posibilidad de que sean piezas que puedan ser analizadas a partir del canon del género dramático ${ }^{1}$.

La pregunta que se plantean estos autores sobre el asunto no solo es pertinente, sino que también hace evidente la dificultad que se presenta al analizar

1. En el estudio introductorio de su edición titulada Autos y coloquios del siglo XVI, Rojas Garcidueñas señala que estamos frente a piezas de dudoso valor literario que «no nos corresponde propiamente analizar» (XXIV). 
estas obras, ya que nuestro acercamiento deberá ser diferente si las concebimos como obras dramáticas destinadas a la representación, o si nos acercamos a ellas partiendo de la base de que se trata de textos en donde lo que destaca es la presencia literaria de la disputa con finalidad educativa. En palabras de Martínez Gómez «el problema que nos planteamos es si estos coloquios se concibieron realmente como obras dramáticas o no, y en caso afirmativo si el autor calculó las posibilidades de su representación» (115). Para responder, la autora recurre a la definición del término «coloquio» de María Moliner, quien lo define como «una composición literaria, no teatral, en forma dialogada». El coloquio es entonces equiparable al diálogo, por lo que Martínez Gómez agrega: «me atrevo a asegurar que los Coloquios de González de Eslava están directamente influenciados por los diálogos, género que proliferó a lo largo del siglo XVI no sólo en España, sino también en parte de Europa, sobre todo Italia» (115).

Influenciados por los diálogos sí, pero destinados a ser representados, como lo indican las acotaciones y las didascalias, para reiterar su función didáctica y presentar dos aspectos contradictorios de un mismo asunto ante un público que más bien solía ser popular.

Lo que se pretende explorar en este trabajo es la influencia de los debates literarios de la Edad Media en los Coloquios espirituales y sacramentales de González de Eslava, analizando en ellos dos parámetros distintos: sus características formales y sus características temáticas.

\section{Características formales: el debate y el diálogo}

Dentro de las características formales deberíamos ser capaces de identificar cuáles son los rasgos propios de esta clase de textos, ya que si bien podemos considerar que la literatura de debate es un género literario propiamente dicho, los debates medievales comparten un esquema básico subyacente, el cual está formado por diferentes factores. En primer lugar, y siempre siguiendo la propuesta de Franchini, nos encontramos con un enfrentamiento verbal entre dos antagonistas que disputan en forma dialéctica algún asunto que para la finalidad del debate es crucial (2001, 17). En los debates medievales cada uno de los participantes trata de persuadir a su contrincante sobre algún asunto trascendental, de la misma forma que se realizaba en las actividades intelectuales universitarias de la época en las disputatio escolásticas.
Los Coloquios espirituales y sacramentales de Eslava comparten esta característica.

No es difícil encontrar en ellos secuencias en donde los personajes se enfrascan en una discusión que resulta sumamente didáctica para el público que está escuchando la obra representada. Ejemplo de esto podría ser el coloquio cuarto o De los cuatro doctores de la Iglesia, en el que dos pastores llamados Cuestión y Capilla se enfrascan en una discusión con San Agustín, San Gerónimo, San Ambrosio y San Gregorio, con el fin de entender el porqué de la redención de los hombres:

$\begin{array}{ll}\text { Cuestión } & \text { Yo te quiero otras cosillas } \\ & \text { preguntar: } \\ & \text { Si su intento fue poblar } \\ & \text { las sillas que están vacantes, } \\ \text { del arte que estaban antes } & \\ \text { que el Ángel fuese a pecar: } \\ \text { ¿Por qué no quiso encarnar } \\ \text { ni bajó } \\ \text { por el Ángel que cayó? } \\ \text { Parece que Dios es cruel, } \\ \text { pues que no nació por él } \\ \text { y por el hombre nació. } \\ \text { Sabrás que el Ángel pecó } \\ \text { gravemente, } \\ \text { diciendo al Omnipotente: } \\ \text { Por mí seré semejante } \\ \text { y desta culpa pesante } \\ \text { no lo fue ni se arrepiente. } \\ \text { Que el gran Dios justo y clemente, } \\ \text { si sintiera } \\ \text { que el ángel se arrepintiera } \\ \text { o de su mal le pesara } \\ \text { cierto Dios lo remediara, } \\ \text { si remedio en él cupiera. (58-59) }\end{array}$

El debate sigue por este camino hasta que los cuatro doctores de la Iglesia logran convencer a los pastores del peso que tiene la razón por la cual Dios decide redimir a los hombres, mas no así a los ángeles caídos. Es preciso destacar en este punto que tanto los cuatro doctores, como los dos pastores, argumentan como si su razonamiento fuese unánime, complementando y perfeccionando sus ideas entre ellos para destacar las dos posturas opuestas del debate. La idea de enfrentar no a dos personajes, sino a dos grupos de personas, es seguramente una decisión destinada a propiciar la teatralidad de la acción, ya que en esa forma se da mayor movimiento a la escena y por lo tanto se incrementa la eficacia dramática. 
En segundo lugar nos encontramos con que en los debates medievales existe un predominio absoluto del diálogo sobre las secuencias narrativas, con lo que poseen un carácter marcadamente dramático. Pueden ser figuras de la vida real o figuras alegóricas. Los debates medievales se dan siempre en forma dialogada. Conservan, de su herencia latina, formas como la del altercado, el conflicto, el diálogo o la disputa.

Por su parte el coloquio implica una conversación o plática que ordinariamente se da entre dos o más personas, con el fin de discutir y debatir un tema relacionado con la doctrina, tratando de conciliar puntos de vista diversos. En los coloquios de Eslava, entonces, encontramos este dominio absoluto del diálogo, ya que son textos construidos para ser representados en los que la oralidad tiene mucho que ver con el espectáculo teatral. Margit Frenk reflexiona sobre la relación entre la puesta en escena de la obra dramática y el auditorio que disfruta de los aspectos orales del teatro, y destaca lo siguiente:

Sin duda la lectura y la recitación de toda clase de obras en las calles y plazas seguía teniendo -lo mismo que en los sermones- mucho en común con el espectáculo teatral, como lo había tenido en la Edad Media [...]. En cuanto al teatro propiamente dicho, no debería hablar aquí yo de él, por razones obvias: se trata del género oído y comunitario por excelencia. Pero sí importa destacar que en el Siglo de Oro la gente parece haber ido a los corrales más para oír que para ver (32).

Oír una representación teatralizada es un entretenimiento colectivo que permitía al espectador entender y aprender las verdades de la doctrina a partir de una percepción física que era a la vez auditiva y visual, personal y colectiva, y que se propiciaba a través de la interacción que se establece entre el actor y el público presente. De esta forma se llevaba a cabo la transmisión de la doctrina o de las verdades de la Fe a un público, sujeto de aprendizaje, que se encontraba ávido de diversión. No olvidemos que se trata de representaciones que se llevan a cabo durante las celebraciones de la fiesta del Corpus.

\section{Características temáticas: filosofía, teología e historia}

Ahora bien, sobre las características temáticas debemos partir del hecho de que en los debates medievales se presenta una enorme variedad temática y seguramente es en esto en lo que radicaba su éxito, tanto entre un público erudito como entre públicos más populares (Franchini 2001, 11). Con todo, en los coloquios de Eslava los temas son más bien limitados ya que, en su mayoría, se trataba de obras que habrían de ser representadas en la festividad del Corpus Christi. De esta manera predominan los temas teológicos y los temas filosóficos. Entre los primeros encontramos varios coloquios en los que entran en conflicto judaísmo y cristianismo, cuyo antecedente directo es la Disputa entre un cristiano y un judio, un texto temprano, de la primera mitad del siglo XIII, que se conserva solamente en forma fragmentada.

Eslava utiliza una serie de alegorías mediante las cuales se suele mostrar el conflicto entre ambas religiones. Por ejemplo en el coloquio octavo o Del Testamento nuevo que hizo Cristo Nuestro Bien, encontramos una discusión entre Ley Vieja y Ley de Gracia. En el texto medieval de la Disputa entre un cristiano y un judio la discusión se sustenta en bases similares a las que posteriormente utilizará el texto novohispano. En el fragmento, que se conserva en la Biblioteca del Escorial, también se enfrentan las ordenanzas contenidas en la ley vieja y la nueva cuando el cristiano interroga al judío: «Di judío: ¿quántas comendanças son de tu ley?» (Franchini 2001, 227).

En el texto novohispano ambas leyes se consideran dignas receptoras de la herencia divina, ya que ambas son hijas legítimas de Dios:

Ley Vieja Hija soy de Dios hoy día, legítima no bastarda, ninguna ley me acobarda, por lo cual la herencia es mía,

Ángel $\quad$ El justicia se me guarda. vosotros no lo guardastes, ni por su ley caminastes; antes como os pareció vosotros lo interpretastes.

Ley VIEja Ea, no me condenes ni me arguyas de delito, para todo me remito al testamento que veis por mano de Dios escrito.

Ley de Gracia Aquí vengo a concederte que ese te lo dio el Criador, mas por su mucho rigor pudo revocarlo en parte en su muerte el testador. 
Y por eso en vano andas

para querer heredar;

no tenéis en que esperar,

que en tu ley todo fue mandas

y en la mía todo es dar.

Ungiome Dios con su aceite,

diome de amor ricas prendas,

porque, Vieja Ley, entiendas

que Dios no toma deleites

en sacrificios y ofrendas. (103)

No es esta la única ocasión en la que González de Eslava pone a debatir personajes que son representantes del Antiguo y del Nuevo Testamento, y en donde se cuestiona la legitimidad del pueblo judío como hijo y heredero de Dios. El tema judío aparece también en los coloquios séptimo y octavo. En el séptimo el profeta Jonás pide ser sacrificado para calmar la furia del mar bajo el argumento de que él (Jonás) es el único en la embarcación que debe cargar con las consecuencias de no cumplir con la voluntad de Dios.

Jonás Sin saber es el saber

del que sin Dios cree que acierta:

quien huye de su querer

camina por vía incierta

y cierto se ha de perder.

Sin Dios no hay cosa ninguna,

sin Dios todo va perdido,

y el que a su saber repugna

con razón es perseguido

con tormenta y fortuna $[\ldots]$.

Si braman los elementos

mi pecado lo causó:

persíganme y den tormentos,

pues cumplen mejor que yo

los divinos mandamientos. (93-94)

Eslava se vale de un anacronismo para construir este coloquio, el resto de los tripulantes y los pasajeros que van en la embarcación son todos cristianos, y no se sienten cómodos con la idea de lanzar al profeta al mar. Jonás los convence pues decide aceptar las consecuencias de su propio pecado, el de desobediencia: «quien huye de su querer / camina por vía incierta». Asimismo Jonás se considera culpable de ser partícipe de un pecado que comparte con todo su pueblo al no haber aceptado la llegada del Mesías: «Sin Dios no hay cosa ninguna, / sin Dios todo va perdido, / y el que a su saber repugna / con razón es perseguido / con tormenta y fortuna» (94).
En el coloquio octavo, el de La Ley Vieja y la Ley Nueva, aparece también un judío que debate con Evangelio sobre la posibilidad de cobrar la herencia divina avalado por los dones que Dios ha otorgado a su pueblo. El judío argumenta que existe una alianza entre ellos y Dios, y que prueba de ello es que Dios les ha permitido sobrevivir al diluvio, les dio el maná para subsistir en el desierto, entregó las Tablas a Moisés y la vara de Aarón. Evangelio en cambio desmonta tales argumentos hablando del sacrificio de Cristo y de su muerte redentora, cuya consecuencia es el triunfo sobre el pecado. En fin, el debate se resuelve con un argumento inapelable, los cristianos cuentan con la pasión de Cristo para conseguir ganar el cielo: "Para bien de los del suelo / esta riqueza nos queda / Estas llagas son moneda / con que los bienes del cielo / granjear el hombre pueda» (112).

No es coincidencia que en los coloquios de Eslava se encuentre en más de una ocasión el debate sobre la controversia religiosa en la que se discute la relación que judíos y cristianos tienen con su $\mathrm{Fe}$ y que al mismo tiempo uno de los dieciséis coloquios, el tercero, esté dedicado a la consagración del primer inquisidor de la Nueva España, don Pedro Moya de Contreras, quien estableció el Tribunal de la Fe en la Ciudad de México y que tenía como una de sus finalidades la identificación de los cristianos nuevos que seguían realizando prácticas judaizantes.

El enfrentamiento entre judaísmo y cristianismo forma parte de otra de las características medievales enumeradas por Franchini, que está relacionada con una cosmovisión dualista del universo en la que nos encontramos con «un mundo polarizado en parejas de contrarios que se oponen para eliminarse o conciliarse» $(2001,19)$.

Otro de los temas teológicos que es importante destacar en los coloquios de Eslava es el de la superioridad de la vida eterna frente a la vida terrenal. Este se presenta en una disputa que se entabla entre la Vida y la Muerte en el coloquio doce o De la Batalla naval que el serenisimo Principe don Juan de Austria tuvo con el Turco. Aquí se combina el tema teológico con un tema histórico, ya que la celebración del triunfo de don Juan de Austria frente a los turcos en 1571 da a Eslava la posibilidad de presentar frente a su público un debate en el que se enfrentan como personajes, la Vida y la Muerte.

Vida abre el coloquio preciándose de sí misma y despreciando el papel que la Muerte desempeña frente a los hombres: 
VIDA ¡Cuán agradable es la Vida!

¡Cuán suave para el hombre!

¡Cuán amada y cuán querida!

Y la muerte, por el hombre,

¡cuán mala y aborrecida!

En la Vida por ser bella

se meten hasta los codos;

la Muerte no quieren vella,

y ella vase tras de todos

y ellos todos huyen della. (152)

La Muerte en cambio considera que Vida es presuntuosa y que bien mirada no es para el hombre "un dulce regalo»; a fin de cuentas, ella, la Muerte es «fea para el que es malo / y hermosa para el que es bueno» (152). El debate se soluciona a lo largo del coloquio en diferentes etapas, ya que entra primero un simple que aborrece a la muerte por su mala figura y tiene para ella calificativos como: «tempestad con truenos», "rana desollada», «vieja tuerta carcomida» (155). Aun así el simple no logra concluir cuál de los dos personajes, Vida o Muerte, es mejor para el hombre. Para descubrir la conclusión del debate el auditorio tendrá que esperar hasta el momento en que aparece un soldado que ha perdido su vida en la batalla contra el Turco, un soldado difunto que va acompañado de un Ángel y a quien Muerte no reconoce, por lo que le pregunta:

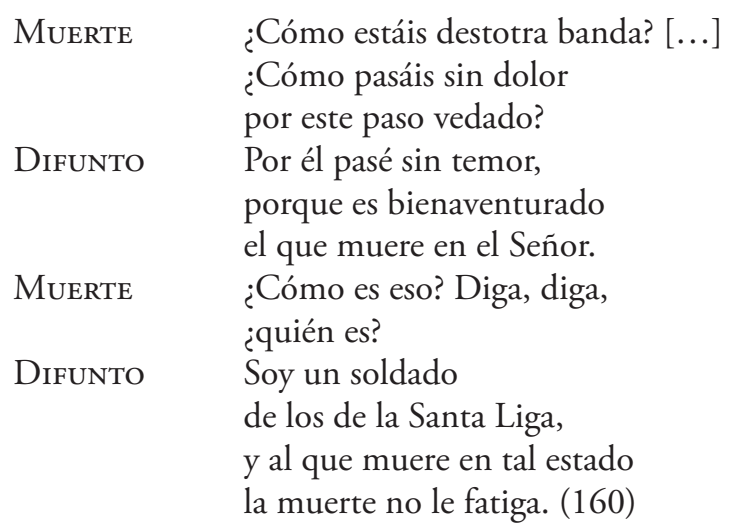

$\mathrm{Al}$ pertenecer a la Santa Liga, una coalición encabezada por Espańa y los Estados Pontificios en contra del Imperio Otomano, el soldado difunto estaba luchando por la defensa de la Fe, y por lo tanto su muerte, como afirma el Ángel, es "por Dios y su servicio" (160), o lo que es lo mismo, se trata de la muerte de un justo, una muerte en gracia de Dios que asegura la vida eterna, con lo que el debate queda resuelto.
Existen otros dos coloquios en los que podemos identificar un tema histórico, el coloquio segundo, Hecho a la jornada que hizo a la China el general Miguel López de Legazpi, cuando se volvió la primera vez de allá a esta Nueva España, en el que se establece un paralelismo entre el peligroso viaje a la China y el que todo hombre ha de realizar de la tierra al cielo. Aquí el debate se constituye tratando de probar cuál es el destino que ofrece a los hombres mayores bondades, ya que si en uno el Simple se regocija porque los habitantes: «... comen pan de mijo» (19), Amor Divino aclara que en el cielo la situación es infinitamente superior, pues «Dios te dará un pan / de la carne de su Hijo» (19).

El tercer coloquio de este grupo con tema histórico es el coloquio quinto, De los siete fuertes. Sobre este texto, Mariscal Hay destaca que se trata de «un aprovechamiento ingenioso de la estrategia de defensa -la construcción de fuertes- ordenada por el Virrey para la guerra en contra de los chichimecas. El importante conflicto, que resultaba de esta segunda conquista española, proporciona a González de Eslava la alegoría que sirve de apoyo al tema doctrinal de su coloquio".

Además de abordar la problemática histórica, en este coloquio nos encontramos ante un texto de tema filosófico en que se presenta un debate entre los vicios para determinar quién de ellos es más efectivo para conquistar al hombre. Una de las particularidades de este texto es que Eslava reviste a los vicios de características indígenas. En él encontramos a Mundo, Demonio y Carne, como chichimecas que portan arco y flecha y que se presentan como enemigos del alma. Este coloquio aborda un tema de gran preocupación en la época: la conquista o pacificación de las tierras al norte de la Nueva España ${ }^{2}$. Concretamente alude a la construcción de fuertes en el camino de México hacia Zacatecas, ordenada por el Virrey en 1570:

El avance de españoles y criollos hacia los yacimientos de plata que había, o se creía que había, en lo que ahora son los estados de Zacatecas, Nuevo León, San Luis Potosí, Guanajuato y Aguas Calientes, territorio habitado por tribus nómadas y semi-nómadas de indios guachichiles, zacatecos, guamares, cazcanes, pames y otomíes, llamados genéricamente «chichimecas» (término peyorativo que significaba 'perro sucio')

2. La guerra a "fuego y sangre» en contra de los chichimecas alzados se declaró en 1567. 
provocó la resistencia de los chichimecas que atacaban con sus arcos y flechas a comerciantes, mineros y administradores que transitaban en la ruta de México a Zacatecas. El Virrey Martín Enríquez de Almanza, después de varios ańos de ataques guerrilleros, declara formalmente la guerra a los chichimecas y ordena la construcción de los fuertes de Ojuelos, Portezuelo, Las Bocas, Ciénaga Grande, Palmillas, Atotonilco y San Felipe. Es a estos fuertes a los que hace referencia González de Eslava en su coloquio (Mariscal Hay).

En la «Loa al virrey» en la que se resume la trama del coloquio, el autor explica que la existencia del Ser Humano está marcada por el pecado original, al que se denomina como chichimeco embravecido. «El Ser Humano encerrado / allí do fue concebido, /fue mortalmente herido / del original pecado, /chichimeco embravecido» (61). El pecado original es caracterizado como un indio chichimeca en boca del personaje Estado de Gracia, capitán del fuerte del Bautismo, quien dice: "Considera, Ser Humano, / que en el vientre maternal / te dio herida mortal / el chichimeco inhumano / de la culpa original» (62). Este pecado original se encarna en los tres personajes alegóricos que son representados como indígenas salteadores de caminos y asesinos. «El Demonio, Carne y Mundo / son chichimecos malditos / que nos espantan con gritos, / que nos llevan al profundo / con gravísimos delitos» (63).

Los tres personajes se enfrascan en una discusión sobre quién es el mejor guerrero para conseguir que Ser Humano se pierda. De entrada, cada uno se asocia con un espacio físico atribuido al imaginario de lo chichimeca. La Carne dice matar con sus manos en los cenagales, el Mundo se esconde en las quebradas, y el Demonio sube a los montes. En su debate, los personajes elogian sus armas, entre las que las flechas son personalizadas con actitudes relacionadas con los pecados mortales y de esa forma describen su modo de perjudicar al hombre. Mundo, que se relaciona con la mentira, utiliza como flecha el engaño, mientras que Demonio, asociado con la soberbia, utiliza tiros de arrogancia e ira. Ambos personajes se reconocen como grandes hacedores de mal, pero aun así declaran que la ganadora de la contienda es la Carne, personificada como mujer y a quien llaman "chichimeca perra». Este personaje que se asocia con la lujuria, es el vicio más efectivo para conquistar al hombre, pues como ella misma dice: «Alabo vuestro valor, / vuestras muertes, vuestros robos, / vuestro ser hambrientos lobos; / mas detrás de mi dulzor / andan los más como bobos» (65).
Tras declarar a la Carne como la ganadora de este debate, el grupo planea el asalto al hombre, el cual se llevará a cabo en el Valle del Mundano Placer en la Venta del Vicio, donde el Ser Humano se detendrá a descansar. Tras expresar su interés por las mujeres que habitan la venta, Ser Humano es atacado por Mundo, Carne y Demonio, que salen gritando y lanzando flechas. Es decir, el deseo sexual que se despierta en el hombre es una expresión del poder maligno de Carne, quien flecha los corazones humanos con el pecado de la lujuria.

Es importante considerar que, dadas las circunstancias de la época, la representación de lo chichimeca en el coloquio no puede ser entendida como la percepción que se tenía del mundo indígena en gene$\mathrm{ral}^{3}$. Es decir, lo chichimeca es asociado a una otredad indomable, los indios insumisos que se resistían a la conquista y a la evangelización y por lo tanto al conocimiento de la bienaventuranza. Son opuestos a los nahuas, mayas, zapotecas, a los grupos del centro y del sur mesoamericano, entre los cuales los procesos de conversión habían sido notablemente más fáciles y efectivos. Los grupos norteños, con sus modelos sociales nómadas y a los que siempre se les atribuyó la falta de religión y gobierno, son la representación de la barbarie en el imaginario colectivo novohispano.

Existe otro coloquio en el que se utiliza la imagen de los chichimecas para personificar a las fuerzas del mal, se trata de El obraje divino, el primer texto de la obra de Eslava. En él se presenta la alegoría del mundo como un taller donde se elaboran paños. Allí, Engaño aparece como mayordomo y se enfrasca en una discusión con Malicia por saber cuál de los dos tiene mayor capacidad para dañar a los hombres. Malicia sale a escena portando arco y flecha con las que traspasa los corazones de las personas. En las palabras de Engaño encontramos la descripción de su apariencia física: "Calla tú, cara de mueca, / y ponte, ponte una rueca, / pues que traes, siendo mujer, / arco como chichimeca» (14).

El arco y la flecha en el mundo prehispánico simbolizan la guerra; lo que resulta aquí de especial interés es que Malicia, como Carne en el coloquio De los siete fuertes, es una mujer, cuya caracterización la acerca más al mundo de la barbarie que al mundo de la civilización. En el pensamiento occidental un personaje que encarna la sensualidad y que va armado

3. Si bien la conquista y evangelización de México se consumó en el siglo Xvi, el territorio hacia el norte se consideró como tierra de guerra viva durante el virreinato. 
de arco y flecha debería de evocar al personaje mitológico responsable de infundir la atracción y el deseo entre las parejas; lejos de ello, Engaño describe los atributos de Malicia de la siguiente manera: «Arco llevas y saeta? / Pareces al dios Cupido» (11). A lo que ella contesta: «Mi tiro es tan encendido / que lleva yerbas secretas / de un malicioso sentido» (11-12). Este tiro es la maledicencia que inflama los corazones de los hombres provocando las desavenencias. En una reinterpretación de la tradición clásica el personaje que se caracteriza como chichimeca, está construido para provocar la desunión entre los hombres.

Por último es preciso fijar nuestra atención en el coloquio trece en el cual se presenta una de las muestras más ricas de la influencia del género del debate en la obra de Eslava. El título revela la tesitura del texto: Coloquio espiritual de la pobreza y la riqueza, que contienden sobre cuál sea la mejor; y es que es precisamente la contienda entre ambos personajes lo que detona y construye la trama de la pieza. Uno de los aspectos más interesantes de este debate es que se manifiesta en múltiples capas: discusión entre pares (Riqueza/Pobreza; Amor propio/Don de Gracia), entre pares con un mediador inferior (Riqueza, Pobreza y Simple) y entre pares con un mediador par (Riqueza, Pobreza y Conocimiento).

Comienza con el enfrentamiento entre Riqueza -quien dice ser «el bien y el consuelo / del que me sigue en el mundo» (163) - y Pobreza, de cuya boca escuchamos: «Por mí Dios vino a buscarme, / por mí fue carne su Verbo» (164). En esta primera parte el lector espectador alcanza a comprender que el valor de Riqueza estriba en el bienestar material que provee en la vida terrenal. El personaje es abiertamente arrogante y desprecia a Pobreza, quien humilde, pero firme, explica al espectador que su valor radica en la vida espiritual y su estrecha relación con Jesucristo.

Riqueza y Pobreza entablan una nueva discusión teniendo como mediador a Simple, el cual, como su nombre indica, muestra poca profundidad de reflexión. Riqueza le pide su intervención: «Dime ¿tú sabrás juzgar / lo que con ésta debato?» (165), y más adelante agrega: «Quítanos de esta baraja / señalando la más dina» (165). Pobreza aprueba a este evaluador diciendo: «Ten juicio tú entre nos, / y veremos cuál escoges / por más buena, de las dos» (165). Simple accede y comienza por preguntar qué beneficios puede recibir de cada una. Riqueza ofrece oro, plata, comida, rentas, mientras que Pobreza le ofrece amor, sosiego. A cada argumento expuesto, Simple expresa su intención de escoger a quien le habla. Es decir, su opinión muda de manera constante. Con esta escena se muestra que el dilema de decidir cuál de las dos es mejor se produce básicamente por ignorancia, por simpleza de juicio. Por lo tanto, para poder resolver el debate es necesario que el mediador sea un par o un superior, alguien capaz de comprender los argumentos expuestos, discernir y resolver. Es por ello que tras el evidente fracaso de la contienda, Pobreza propone elegir a un juez discreto: «úzuguelo el conocimiento, / que en todas cosas acierta: / quede a él nuestra reyerta» (166).

Para llevar a cabo su misión, Conocimiento les pide a ambas que se desnuden para ver su verdadera esencia. De esta manera, el espectador presencia la gran diferencia entre el ser y el parecer. En el exterior, Pobreza es desagradable y Riqueza bella, pero al quitarse la ropa la primera tiene el cuerpo cubierto de estrellas y un crucifijo pintado en el pecho, mientras que la segunda es un demonio. Sin embargo, se explica que la Riqueza no puede ser considerada como un aliado del mal o un vicio: "la Riqueza no es mala, / sino solo usar mal de ella» (172). Incluso cuando el personaje se ve desnudo a sí mismo, tras la petición de Conocimiento, se sorprende de su propio cuerpo y se avergüenza del mismo: «Mi corazón se desmaya, / que no quiero verme aquí, / pues no me veo cual me vi, / no sé, triste, dó me vaya / para esconderme de mí» (171).

En esta contrariedad el personaje alegórico muestra un conflicto interno provocado por una imagen distorsionada de sí mismo. Esto lleva al espectador a comprender que a pesar de la importancia que se le da a la riqueza en el mundo, su valor intrínseco es bajo. La solución al dolor que siente Riqueza ante la revelación de su fealdad verdadera es proporcionada por Conocimiento, quien le encamina al sacramento de la penitencia: «El rincón de Penitencia / puedes tomar por guarida, / de allí saldrás bien vestida / con las ropas de excelencia / de la enmienda de la vida» (171).

El triunfo de la Pobreza en la contienda se resume en las palabras que Conocimiento dirige a la audiencia: «Ten, cristiano, regocijo / de ser pobre acá en el suelo, / tenlo por muy gran consuelo / pues Dios te tiene por hijo / para que heredes el cielo» (172). De manera que el coloquio trece culmina con el resultado de la contienda en la voz del juez discreto que remata el debate en los siguientes términos:

\section{Conocimiento La Pobreza aquí se siente,} porque ha de triunfar hoy ella. La corona de consuelo lleve de inmortal memoria, 
y esta palma de victoria,

y así triunfe acá en el suelo

hasta que triunfe en la gloria. (173)

\section{Conclusión}

Como se ha podido ver, la fusión que González de Eslava logra entre el género de debate y la teatralización del texto contribuye a construir la función didáctica de sus coloquios. Al poner a los personajes a discutir frente a diferentes mediadores de muy diversa formación y capacidad de juicio, el autor logra que la resolución del debate se desenvuelva en forma graduada. Esto favorece en el espectador una comprensión que va in crescendo dándole al debate mayor fuerza de persuasión frente a la audiencia.

Por otra parte, la presencia del simple que se repite en varios de los coloquios analizados es siempre el primer paso para la presentación del problema a debatir. En todos los casos, personajes como Ignorancia y Simple aportan también su postura frente al debate, pero esta suele ser poco informada, representante del pensamiento popular y no reflexiva, destinada a despertar el interés del auditorio y provocar la risa fácil. En esta primera etapa del debate, los personajes de simples o pastores suelen representar el pensamiento de los destinatarios a los que el autor desea apelar. En un segundo estadio del debate, se recurre a un juez que representa a una figura de autoridad como Conocimiento, Evangelio, un Ángel, Discreción Divina, Saber, entre otros, que con mayor grado de información solucionan la disputa. A través de los argumentos de la figura de autoridad y de su resolución de la contienda se expone la doctrina que está siempre relacionada con el buen obrar del ser humano destinado a conseguir la salvación de su alma. Tanto a través de las características formales como las características temáticas González de Eslava construye una conjunción entre el género del debate medieval y el teatro doctrinal novohispano.

\section{Bibliografía}

Franchini, Enzo. Los debates literarios en la Edad Media. Madrid: Ediciones del Laberinto (Arcadia de las Letras 9), 2001.

Franchini, Enzo. «Debates medievales castellanos». Carlos Alvar y José Manuel Lucía Megías (coords.). Diccionario Filológico de Literatura Medieval Española. Textos y transmisión. Madrid: Castalia, 2002: 376-390.

FrenK, Margit. Entre la voz y el silencio. Alcalá de Henares: Centro de Estudios Cervantinos, 1997.

González de Eslava, Fernán. Coloquios espirituales y sacramentales y poesías sagradas. Joaquín García Icazbalceta (ed.). México: Imprenta de Francisco Díaz de León, 1877.

MarisCal HaY, Beatriz. «Del contexto histórico al contexto literario: observaciones sobre los Coloquios espirituales de Fernán González de Eslava». Raúl Marrero-Fente (ed.). Perspectivas trasatlánticas. Estudios coloniales hispanoamericanos. Madrid: Verbum, 2004: 93-102. Consultado en http://www.cervantesvirtual. com/obra-visor/del-contexto-historico-al-contextoliterario-observaciones-sobre-los-coloquios-espirituales-de-fernan-gonzalez-de-eslava-0/html/ a38fd14a-9d3e-417d-bfb2-e1dd33ff4b8e_3.html. Fecha de acceso: 10 jul. 2016.

Martínez Gómez, Juana. «Algunas consideraciones sobre el Coloquio XVI de Fernán González de Eslava». Anales de Literatura Hispanoamericana, 9 (1980): 113133. Consultado en http://revistas.ucm.es/index.php/ ALHI/article/view/ALHI8080110113A. Fecha de acceso: 10 jul. 2016.

Moliner, María. Diccionario de uso del español. Madrid: Gredos, 1966-1967. 2 vols.

Rojas Garcidueñas, José. Autos y coloquios del siglo XVI. México: UNAM, 1939. 
